\title{
Ecomorphological inferences in early vertebrates: reconstructing Dunkleosteus terrelli (Arthrodira, Placodermi) caudal fin from palaeoecological data
}

\author{
Humberto G Ferrón ${ }^{\text {Corresp.. }}{ }^{1}$ ， Carlos Martínez-Pérez ${ }^{1,2}$, Héctor Botella ${ }^{1}$ \\ ${ }^{1}$ Cavanilles Institute of Biodiversity and Evolutionary Biology, University of Valencia, Paterna, Spain \\ 2 School of Earth Sciences, University of Bristol, Bristol, United Kingdom \\ Corresponding Author: Humberto G Ferrón \\ Email address: Humberto.Ferron@uv.es
}

Our knowledge about the body morphology of many extinct early vertebrates is very limited, especially in regard to their post-thoracic region. The prompt disarticulation of the dermo-skeletal elements due to taphonomic processes and the lack of a well-ossified endoskeleton in a large number of groups hinder the preservation of complete specimens. Previous reconstructions of most early vertebrates known from partial remains have been wholly based on phylogenetically closely related taxa. However, body design of fishes is determined, to a large extent, by their swimming mode and feeding niche, making it possible to recognise different morphological traits that have evolved several times in nonclosely related groups with similar lifestyles. Based on this well-known ecomorphological correlation, here we propose a useful comparative framework established on extant taxa for predicting some anatomical aspects in extinct aquatic vertebrates from palaeoecological data and vice versa. For this, we have assessed the relationship between the locomotory patterns and the morphological variability of the caudal region in extant sharks by means of geometric morphometrics and allometric regression analysis. Multivariate analyses reveal a strong morphological convergence in non-closely related shark species that share similar modes of life, enabling the characterization of the caudal fin morphology of different ecological subgroups. In addition, interspecific positive allometry, affecting mainly the caudal fin span, has been detected. This phenomenon seems to be stronger in sharks with more pelagic habits, supporting its role as a compensation mechanism for the loss of hydrodynamic lift associated with the increase in body size, as previously suggested for many other living and extinct aquatic vertebrates. The quantification of shape change per unit size in each ecological subgroup has allowed us to establish a basis for inferring not only qualitative aspects of the caudal fin morphology of extinct early vertebrates but also to predict absolute values of other variables such as the fin span or the hypocercal and heterocercal angles. The application 
of this ecomorphological approach to the specific case of Dunkleosteus terrelli has led to a new reconstruction of this emblematic placoderm. Our proposal suggests a caudal fin with a well-developed ventral lobe, narrow peduncle and wide span, in contrast to classical reconstructions founded on the phylogenetic proximity with much smaller placoderms known from complete specimens. Interestingly, this prediction gains support with the recent discovery of fin distal elements (ceratotrichia) in a well preserved $D$. terrelli, which suggests a possible greater morphological variability in placoderm caudal fins than previously thought. 


\section{Ecomorphological inferences in early vertebrates:}

2 reconstructing Dunkleosteus terrelli (Arthrodira, Placodermi)

3 caudal fin from palaeoecological data

4 Humberto Gracián Ferrón ${ }^{1}$, Carlos Martínez-Pérez ${ }^{1,2}$, Héctor Botella ${ }^{1}$

$5{ }^{1}$ Cavanilles Institute of Biodiversity and Evolutionary Biology, University of Valencia, Valencia, Valencian

6 Community, Spain

$7 \quad{ }^{2}$ School of Earth Sciences, University of Bristol, Bristol, UK

Corresponding Author:

Humberto G. Ferron ${ }^{1}$ 


\section{ABSTRACT}

23 Our knowledge about the body morphology of many extinct early vertebrates is very limited,

24 especially in regard to their post-thoracic region. The prompt disarticulation of the dermoskeletal elements due to taphonomic processes and the lack of a well-ossified endoskeleton in a large number of groups hinder the preservation of complete specimens. Previous reconstructions of most early vertebrates known from partial remains have been wholly based on phylogenetically closely related taxa. However, body design of fishes is determined, to a large extent, by their swimming mode and feeding niche, making it possible to recognise different morphological traits that have evolved several times in non-closely related groups with similar lifestyles. Based on this well-known ecomorphological correlation, here we propose a useful comparative framework established on extant taxa for predicting some anatomical aspects in extinct aquatic vertebrates from palaeoecological data and vice versa. For this, we have assessed the relationship between the locomotory patterns and the morphological variability of the caudal region in extant sharks by means of geometric morphometrics and allometric regression analysis. Multivariate analyses reveal a strong morphological convergence in non-closely related shark species that share similar modes of life, enabling the characterization of the caudal fin morphology of different ecological subgroups. In addition, interspecific positive allometry, affecting mainly the caudal fin span, has been detected. This phenomenon seems to be stronger in sharks with more pelagic habits, supporting its role as a compensation mechanism for the loss of hydrodynamic lift associated with the increase in body size, as previously suggested for many other living and extinct aquatic vertebrates. The 
quantification of shape change per unit size in each ecological subgroup has allowed us to establish a basis for inferring not only qualitative aspects of the caudal fin morphology of extinct early vertebrates but also to predict absolute values of other variables such as the fin span or the hypocercal and heterocercal angles. The application of this ecomorphological approach to the specific case of Dunkleosteus terrelli has led to a new reconstruction of this emblematic placoderm. Our proposal suggests a caudal fin with a well-developed ventral lobe, narrow peduncle and wide span, in contrast to classical reconstructions founded on the phylogenetic proximity with much smaller placoderms known from complete specimens. Interestingly, this prediction gains support with the recent discovery of fin distal elements (ceratotrichia) in a well preserved $D$. terrelli, which suggests a possible greater morphological variability in placoderm caudal fins than previously thought.

\section{INTRODUCTION}

The fossil record provides a unique and fascinating glimpse into the lives of extinct creatures that once inhabited the Earth. Unfortunately, the palaeobiological information contained in the fossils is, in most cases, rather incomplete owing to different taphonomical processes (Allison \& Bottjer, 2011 and references therein). In consequence, the understanding of numerous anatomical, ecological or evolutive aspects of extinct (but also living) organisms largely rely on the application of novel statistical procedures and specialized analytical methods that allow testing and compensating such preservational biases (Harper, 2008; Sepkoski \& Ruse, 2009).

The presence or absence of mineralized tissues constitutes one of the main biasing factors in this sense, constraining in a considerable way the preservation potential of some groups or 
64 specific anatomical structures (e.g., Allison, 1986; Allison \& Briggs, 1993; Briggs \& Kear, 1993;

65

Kidwell \& Flessa, 1996; Briggs, 2003; Allison \& Bottjer, 2011). Among vertebrates, skeleton mineralization occurred in the Cambrian at very early stages in the evolution of the group (Donoghue \& Sansom, 2002), with the appearance of tooth-like structures in conodonts and dermo-skeletal elements, such as large bony plates or minute scales, in more derived forms (Sansom et al., 1992; Donoghue \& Sansom, 2002; Donoghue, Sansom \& Downs, 2006; Sire, Donoghue \& Vickaryous, 2009; Murdock et al., 2013). However, large dermal plates are typically restricted to the cephalo-thoracic region in early vertebrate groups (e.g., placoderms and most agnathan ostracoderms), and in the vast majority of cases scales, that normally cover the whole body surface, disarticulate to isolated elements during preservation (Janvier, 1996). In consequence, although the fossil record of these mineralized structures is very abundant, they provide very little information about the whole external aspect of these animals. The late evolution of well-ossified endoskeletons in Silurian times (only present in osteichthyes) (Donoghue \& Sansom, 2002; Donoghue, Sansom \& Downs, 2006) just aggravates this problem, leading in conjunction to a very vague idea of the general body shape and size of a big number of Palaeozoic early vertebrate representatives, especially in regard to their post-thoracic region.

Previous reconstructions of most early vertebrates known from partial remains have been wholly based on phylogenetically closely related taxa (see some examples in Frickhinger, 1995; Janvier, 1996; Long, 2010; Cuny, 2013). However, the morphology of all biological structures is the result of a combination of several factors, including not only the phylogenetic legacy of the group but also morphogenetic, environmental and functional aspects (Seilacher, 1991). Interestingly, the shape of the body and the fins of living aquatic vertebrates is determined, to a 
86 large extent, by their swimming mode (e.g., Breder, 1926; Webb, 1975, 1988; Lindsey, 1978;

87 Webb \& Buffrénil, 1990; Thomson \& Simanek, 1997; Sfakiotakis, Lane \& Davies, 1999) and

88 feeding niche (Webb, 1984). In fact, the functional constraints of different types of locomotion

89 are so strong that different ecomorphotypes of fishes are clearly recognizable (e.g., Breder,

1926; Webb, 1975; Lindsey, 1978), having evolved several times in non-closely related groups

91 adapted to similar lifestyles (Lindsey, 1978; Fletcher et al., 2014).

92 Thus, given the well-recognized relationship between the mode of life and body pattern in

93 living aquatic vertebrates, we propose that the identification of ecomorphological relationships

94 and the morphometric characterization of ecomorphotypes could be very useful for inferring

95 the morphology of some missing structures in early vertebrate taxa. In this sense, living sharks

96 can be considered as a suitable modern group for exploring this issue, showing an important

97 ecological diversity and a wide range of body sizes. With this aim, we have assessed the

98 relationship between the locomotory patterns and the morphological variability of the caudal

99 region in extant sharks by means of geometric morphometrics and allometric regression

100 analysis. We present a comparative framework for predicting some anatomical aspects in

101 extinct species from palaeoecological data, and vice versa.

\section{Dunkleosteus terrelli as a case of study}

103

104

105

106

Dunkleosteus terrelli, a giant carnivorous placoderm that inhabited the seas of Euramerica during the Late Devonian (Carr, 2010; Carr \& Jackson, 2010), constitutes one of the most representative examples in this regard. This large apex predator was equipped with sharp bladed jaws and one of the most rapid and powerful bites known in both living and extinct 
107 animals (Anderson \& Westneat, 2007, 2009). Given its large size and fearsome appearance, $D$.

108 terrelli has been the focus of interest for the general public during decades, becoming one of

109 the most iconic fossils in the latter years. However, despite popular interest in the species $D$.

110 terrelli is only known from disarticulated plates of the head shield, and a few articulated

111 remains of incomplete pectoral fins (Carr, 2010; Carr, Lelièvre \& Jackson, 2010). For this reason,

112 its general body shape and size remain unknown and to date reconstructions of $D$. terrelli have

113 relied on the morphology of smaller arthrodire placoderms known from complete specimens

114 (e.g., Coccosteus in Heintz, 1932). As a consequence, some anatomical features of these taxa,

115 such as the presence of tails with low heterocercal angles and poor developed ventral lobes

116 and/or macruriform bodies, have been usually represented in publications and palaeoartistic

117 reconstructions of D. terrelli (e.g., Heintz, 1932 fig. 90; Carr, 1995 fig. 17; Frickhinger, 1995 p.

118 136; Cuny, 2013 fig. 7). Here, based on the established ecomorphological framework, we

119 propose a more parsimonious reconstruction of the caudal region of this flagship species from

120 an ecological-proximity criterion, assuming analogy with living active pelagic sharks on the basis

121 of morphological (Barron \& Ettensohn, 1981), biomechanical (Anderson \& Westneat, 2009),

122 paleobiogeographic (Carr, 2009; Carr \& Jackson, 2010) and taphonomic evidence (Carr, 2010;

123 Carr \& Jackson, 2010) (see Discussion section for a detailed assessment of the ecology of this 124 taxon).

125 MATERIALS \& METHODS

126 Geometric morphometrics, PCA and regression analyses in sharks 
127 Morphological variability of the caudal region of extant sharks was analysed in a selection of 31

128 species spanning the ecological, morphological and taxonomical diversity of the group (see Data

129 S1). We have defined 8 landmarks of type 1 and type 2 (Fig. 1A) that were digitized on lateral-

130 view illustrations of sharks from Ebert, Fowler \& Compagno (2013) by means of tpsDig1

131 software v.1.4 (Rohlf, 2004). The superimposition of landmark configurations was carried out

132 with Generalized Procrustes Analysis (GPA) using MorphoJ software v. 1.06d (Klingenberg,

133 2011). This procedure allows the removal of variations in translation, rotation and size from the

134 original landmark configurations. Procrustes coordinates were transformed into a covariance

135 matrix and subjected to principal component analysis (PCA) also with MorphoJ software v.

136 1.06d (Klingenberg, 2011). The degree of homoplasy was checked by plotting the phylogeny of

137 the studied species on the PCA morphospace and PCA results were interpreted categorizing

138 sharks both into taxonomic groups (at order level) and according to their mode of life or

139 locomotion capabilities (following the classification of Thomson \& Simanek, 1997 in demersal,

140 squalomorph, generalised and fast swimming pelagic sharks; the last two groups were reunified

141 here into active pelagic sharks). Phylogenetic signal was checked in MorphoJ software v. 1.06d

142 (Klingenberg, 2011) considering the phylogenetic relationships proposed by Vélez-Zuazo \&

143 Agnarsson (2011). Regression analyses between shape and total body length were performed

144 for both the totality of sharks and each of the ecological subgroups in order to detect allometric

145 changes in caudal fin morphology (two additional landmarks were considered for the analysis of

146 active pelagic sharks, Fig. 1B). For that, a permutation test (number of permutations $=10000$ )

147 was carried out using tpsRegr v.1.4.1 (Rohlf, 2011) and MorphoJ software v. 1.06d (Klingenberg,

148 2011). The expected caudal fin morphology of $D$. terrelli was inferred from its total body length 
149 estimates (see below) by interpolation in the regression analysis of active pelagic sharks

150 assuming ecological affinity. Finally, Pinocchio effect (which refers to the fact that variance seen

151 at some specific landmarks is distributed across all landmarks during Procrustes

152 Superimposition; von Cramon-Taubadel, Frazier \& Lahr, 2007) was tested comparing RFTRA

153 (Resistant Fit Theta-Rho Analysis) and GPA superimpositions in IMP software CoordGen8

154 (Sheets, 2014). A validation test was performed by inferring the caudal fin morphology of

155 several living shark species spanning the phylogeny of the group and covering a wide range of

156 body sizes.

157 Total body length estimation of Dunkleosteus terrelli

158 Total body length of $D$. terrelli was estimated in a regression analysis between the total body

159 length (TBL) and the upper jaw perimeter (UJP) of 245 extant sharks, belonging to 14 different

160 species, from morphometric data compiled in Lowry et al. (2009) (Data S2). UJP was measured

161 in four assembled (skull and thoracic armor) specimens of $D$. terrelli hosted in the Cleveland

162 Museum (Ohio, USA) (CMNH 5768, CMNH 7424, CMNH 6090, CMNH 7054). Measurements

163 were taken contouring the anterior margin of the suborbital, postnasal and rostral plates and

164 considering quadratomandibular articulations as endpoints (Fig. 1C). However, the remains of

165 the largest $D$. terrelli described up to date consist of an isolated partial inferognathal that only

166 preserves the anterior half (CMNH 5936). As a consequence UJP cannot be directly measured

167 on this specimen for body length estimations. For this reason, UJP of CMNH 5936 was

168 approximated from additional regression analyses between the UJP and five inferognathal

169 metric variables (JM1-5) measured on the four assembled specimens (Fig. 1D). 
170 RESULTS

171 Geometric morphometrics, PCA and regression analyses in sharks

172 Comparison between GPA and RFTRA superimpositions has allowed us to discard the existence

173 of a Pinocchio effect in all the performed analyses (Data S3). Significant phylogenetic signal has

174 been detected neither in the whole group of sharks (P-value: 0.18 ) nor in any ecological

175 subgroup (P-value: $0.44,0.31$ and 0.48 for demersal, squalomorph and active pelagic sharks,

176 respectively). PCA results for the whole group of sharks are shown in Fig. 2. PC1 explains $41.7 \%$

177 of the total variance whereas PC2 explains 32.7\%. The observed morphological variability in

178 caudal fins of sharks can be summarized in shape changes affecting mainly the relative fin span

179 (represented by PC1 axis) and fin length (represented by PC2 axis). The mapped phylogeny and

180 the distribution of taxonomic groups within the PCA graph reveal an important degree of

181 morphological homoplasy in the caudal fin of species from different orders (Fig. 2A).

182 Conversely, groups defined by Thomson \& Simanek (1997), which reflect different modes of

183 life, occupy more localized distributions within the PCA morphospace (Fig. 2B). Demersal

184 sharks, restricted mainly to the highest values in PC1, are characterized by caudal fins with low

185 spans; squalomorph sharks, occupying intermediate values in PC1 and high values in PC2, are

186 characterized by comparatively short caudal fins; and, finally, active pelagic sharks, situated in

187 the lowest values of PC1, are characterized by caudal fins with wide spans. Positive allometry

188 affecting mainly caudal fin span has been detected in the whole group of sharks (P-value <

189 0.001), squalomorphs (P-value: 0.097, significant at alpha $=0.1)$ and active pelagic sharks $(\mathrm{P}$ -

190 value: 0.009), whereas no allometric changes have been found in demersal sharks (P-value: 
1910.380 ) (Fig. 3). Validation analysis shows that the established methodological framework is able 192 to properly predict the caudal fin morphology of the vast majority of tested sharks (confined 193 within the individual confidence interval boundaries) (Fig. S1).

\section{Total body length estimation and caudal fin reconstruction of Dunkleosteus terrelli}

Values for UJP and JMs of $D$. terrelli studied specimens are given in Table 1. Regression analysis between both variables shows a good fit to a linear model ( $R^{2}$ above 0.9 in all cases; Table 2$)$. Estimates of UJP for CMNH 5936 specimen ranged between $118.2 \mathrm{~cm}$ and $163.8 \mathrm{~cm}$ (Table 2), but $155.7 \mathrm{~cm}$ has been considered as the most accurate estimate, obtained from the best-fitted regression model, and has been used for subsequent steps. Regression analysis between UJP and TBL raw data of extant sharks also shows a good fit to a linear model $\left(R^{2}=0.86, T B L(c m)=\right.$ $5.33 *$ UJP $(\mathrm{cm})+48.66)$. Total body lengths estimations of 3.20, 5.34, 5.76, 6.88 and 8.79 meters were obtained for $D$. terrelli specimens CMNH 5768, CMNH 7424, CMNH 6090, CMNH 7054 and CMNH 5936 respectively.

Predicted caudal fin morphologies for each of the $D$. terrelli specimens show well-developed ventral lobes, narrow peduncles, wide spans and high heterocercal and hypocercal angles (ranging from $22^{\circ}$ to $30^{\circ}$ and from $44^{\circ}$ to $47^{\circ}$ respectively) (Fig. 4A). Reconstruction of the largest specimen $(8.79 \mathrm{~m})$ is shown in Fig. 4B, with the highest caudal fin heterocercal and hipocercal angles $\left(30^{\circ}\right.$ and $47^{\circ}$ respectively), the best-developed ventral lobe $(1.26 \mathrm{~m})$ and the widest fin span.

\section{DISCUSSION}




\section{Ecomorphological traits of shark caudal fin}

212 Caudal fin morphology and locomotion capabilities of sharks. Body design of aquatic

213 vertebrates is closely related with swimming mode (e.g., Breder, 1926; Webb, 1975, 1988;

214 Lindsey, 1978; Webb \& Buffrénil, 1990; Thomson \& Simanek, 1997; Sfakiotakis, Lane \& Davies, 215 1999) and feeding niche (Webb, 1984). This morphological convergence is especially noticeable

216 in the shape and size of the body and caudal fin of the groups where the tail is the main

217 structure involved in thrust generation (body-caudal fin propulsion) (Lindsey, 1978). Here, the

218 study of the caudal fin morphological variation of 31 different species of sharks provides

219 additional evidence in this sense, showing a strong morphological convergence in non-closely

220 related shark species that share similar modes of life (compare Fig. 2A and B). The shark body

221 patterns proposed by Thomson \& Simanek (1997) are recognizable after our morphometric

222 analysis as extremes of a morphological continuum which is probably due to a graduation in

223 locomotion capabilities (Fig. 2B). On the other hand, some specific morphological features, such

224 as thunniform body and/or caudal fins with high aspect ratio, have evolved independently in

225 both living and extinct groups of aquatic vertebrates adapted to strong continuous swimming

226 (Motani, 2002; Donley et al., 2004; Lindgren et al., 2010, Lindgren, Kaddumi \& Polcyn, 2013).

227 Accordingly, our results support a notable homogeneity in the caudal fin morphology of active

228 pelagic sharks, most of them sharing the possession of a well-developed ventral lobe and wide

229 caudal fin span (Fig. 2B) that maximizes thrust and minimizes drag and recoil energy losses

230 (Langerhans \& Reznick, 2010). 
231 Caudal fin allometry of sharks. Besides ecology, this study suggests that caudal fin morphology

232 of sharks is also influenced by body size. We have found interspecific positive allometry

233 affecting mainly the caudal fin span (Fig. 3A). This same phenomenon has been previously

234 reported during the ontogeny of some phylogenetically distant aquatic vertebrates, including

235 chondrichthyans (Fu et al., 2016), osteichthyans (Arata, 1954; Nakamura, 1985), cetaceans

236 (Lingham-Soliar, 2005) and even fossil groups such as ichthyosaurs (Motani, 2002). The

237 presence of this particular trend in so disparate groups responds to common physiological constraints. There is evidence that increased size results in lower muscle contraction frequency

(Altringham \& Johnston, 1990; Altringham \& Young, 1991), which results in lower tail beat

240 frequency (Wardle, 1975). Consequently, a loss in swimming speed and hydrodynamic lift is compensated with proportionally wider caudal fin spans (Motani, 2002; Lingham-Soliar, 2005).

As expected, we have detected this phenomenon only in sharks with comparatively good swimming capabilities (i.e., squalomorph and active pelagic species, Fig. $3 C$ and D) whereas it is absent in demersal species where hydrodynamic lift is not as important, with decreased need to control their position in the water column (Fig. 3B). These findings imply further evidence supporting the involvement of the caudal fin allometry found in many aquatic vertebrate groups as a compensation mechanism for the loss of hydrodynamic lift associated with the increase in body size.

Scope and limitations of the framework. Our work is the first to establish a comparative framework with geometric morphometrics of body-caudal fin propulsion on which to base ecomorphological inferences of extinct early vertebrates with body-caudal fin propulsion. The high predictive power of this methodology is demonstrated by the validation analysis, being 
253 able to properly infer the caudal fin morphology of an important number of the examined 254 species (Fig. S1). We propose that this approach is applicable for both: (1) predicting some 255 missing morphological information of the caudal fin region based on palaeoecological data, and

256 (2) inferring swimming capabilities or some other ecological traits in species known from well-

257 preserved complete specimens. The range of extinct taxa that could be potentially included in 258 this model encompasses an important number of early vertebrates, including different groups

259 of gnathostomes (e.g., many extinct groups of chondrychthyans, placoderms and

260 'acanthodians') and presumably a few agnathans with epicercal tails (e.g., osteostracans)

261 (Janvier, 1996). However, the influence of structures that contribute to bouyancy (i.e., liver,

262 swim bladders or lungs) on the allometric scaling factor of caudal fin spans should be quantified

263 in future studies in order to improve the methodology here proposed and increase the accuracy

264 of the derived predictions. Until then, this proposal can be considered as a suitable first-

265 attempt model for supporting ecomorphological inferences of extinct early vertebrates.

Dunkleosteus terrelli as a case study. The lack of preserved post-thoracic remains of large pelagic arthrodires and the small size of the species known from complete specimens (see Denison, 1978) make it difficult to base ecomorphological inferences of $D$. terrelli on other placoderms. We propose that living sharks can be considered as suitable models for predicting characters strongly correlated with the lifestyle in placoderms, in cases like this, where no other

271 closer related taxa with similar ecology are known. As in modern sharks, arthrodire placoderms were also body-caudal fin propulsors, generating thrust with lateral movements of their tails

273 (Denison, 1978). Consequently, caudal fin morphology of $D$. terrelli, as the main propulsor 
274 organ, should also be subject to strong selection pressures driven by ecology, locomotion and 275 body size.

276 Ecology of Dunkleosteus terrelli. Both the lifestyle and trophic position of this species are

277 relatively well known regardless of the virtual absence of post-thoracic remains. $D$. terrelli has 278 been interpreted as a placoderm with good swimming capabilities, probably being able to 279 actively pursue its prey (Heintz, 1932; Carr, 1995). Recently, Carr (2010) has provided strong 280 statistical evidence for active pelagic cruising in this species, based on taphonomical and 281 sedimentological data. Furthermore, palaeogeographical data is in accordance with such 282 inferences. Fossil remains of $D$. terrelli have been reported from the Upper Devonian of both 283 the Appalachian Basin (EEUU) and the Tafilalt Basin (Morocco), suggesting a Euramerican 284 distribution and supporting that this species was able to disperse throughout the Rheic Ocean, 285 an ancient deep water biogeographic barrier (Carr, 2009; Carr \& Jackson, 2010). Classically, anguilliform swimming mode, which implies large amplitude undulations of the whole body

287 (Lindsey, 1978), has been presupposed for small elongated species and extrapolated for the 288 entire group of placoderms (Stensiö, 1963; Thomson, 1971). However, more recently, some authors called into question this assumption proposing that other swimming modes could also be present within placoderms (Carr, 1995; Carr, Lelièvre \& Jackson, 2010). In fact, anguilliform propulsion seems unlikely for most representatives of this group as the presence of the cephalic shield limits lateral movements of the head and part of the trunk (Carr, 1995). In consequence, other more efficient swimming modes such as subcarangiform or even thunniform, where undulations are restricted to the posterior part of the body (Lindsey, 1978), could be more plausible for at least some pelagic placoderms. 
296 On the other hand, regarding trophic position, big arthrodires were situated at the top of the

297 Late Devonian marine trophic pyramids constituting the earliest case of apex predatory

298 vertebrates (Anderson \& Westneat, 2009; Lamsdell \& Braddy, 2009). The presence of powerful

299 jaws, extremely fast bite and suction feeding mechanisms suggests predation on evasive, free-

300 swimming and armoured animals, for example arthropods, ammonoids or other placoderms

301 (Anderson \& Westneat, 2009). In addition, some other anatomical evidence such as the

302 terminal position of the mouth, the lateral compression of the body and the reduction of the

303 thoracic shield and pectoral spines also support a predatory lifestyle in the water column

304 (Barron \& Ettensohn, 1981 and references therein). Besides all these indirect inferences, teeth

305 of a small chondrichthyan (i.e., Orodus) have been discovered in association with $D$. terrelli

306 remains and regarded as putative stomach contents (Carr \& Jackson, 2010), thus constituting a

307 possible direct evidence of the diet of this massive placoderm (but see Williams, 1990).

308 Interestingly, Orodus spp. have been interpreted as tachypelagic chondrichthyans (i.e., high-

309 speed pelagic species) according to the general morphology of some complete specimens from

310 the Pennsylvanian (Carboniferous) (Compagno, 1990) and the arrangement and morphology of

311 their dermal denticles, comparable to those of the scales of living fast pelagic shark (Raschi \&

312 Musick, 1986). In summary, taken altogether, the evidence support that $D$. terrelli was a big

313 cruiser with good swimming capabilities, situated at the top of the trophic pyramid as active

314 predator. In consequence, both the ecology and trophic position of this species, and probably

315 other big arthrodires, are comparable to those of living active pelagic sharks, being possible to

316 establish an ecological analogy between both groups. 
317 Body size of Dunkleosteus terrelli. Previous references to the size of $D$. terrelli are not based

318 on quantitative approaches (Denison, 1978; Frickhinger, 1995; Anderson \& Westneat, 2007,

319 2009; Albert, Johnson \& Knouft, 2009; Carr, 2010; Long, 2010) and some of them are probably

320 overestimates (e.g., 10 meters in Anderson \& Westneat, 2009). Size estimations of other big

321 placoderms have been founded on corporal proportions of Coccosteus, extrapolating the ratio

322 between some shield measurements and total body length calculated in complete specimens of

323 this species (e.g., Gross, 1960; Young, 2005; Vaškaninová \& Kraft, 2014). However, the reliability

324 of such approximations should be questioned since the obtained estimates are too far from the

325 usual range of lengths of Coccosteus cuspidatus (one order of magnitude higher) and the

326 presence of allometry has been documented many times in some shield plates of different

327 species (e.g., Werdelin \& Long, 1986; Zhu \& Janvier, 1996; Trinajstic \& McNamara, 1999;

328 Trinajstic \& Hazelton, 2007; Olive et al., 2014), including C. cuspidatus itself (Miles \& Westoll,

329 1968). Therefore, basing total body length estimations of $D$. terrelli on other placoderms could

330 be again inadequate and different approaches should be applied. In this sense, some previous

331 works have used extant sharks as useful models for estimating other body variables in

332 placoderms (see Carr, 2010). Here, we have approximated the size of $D$. terrelli using the

333 relationship between the total body length and the upper jaw perimeter established from

334 several species of extant big pelagic sharks. A total body length of $8.79 \mathrm{~m}$ has been inferred for

335 the biggest specimen of $D$. terrelli ( $\mathrm{CMNH}$ 5936), being considerably larger than some of the

336 previous more conservative estimates (e.g., between 4 and $5 \mathrm{~m}$ in Long, 2010; $4.6 \mathrm{~m}$ in Carr,

337 2010; and $6 \mathrm{~m}$ in Denison, 1978 and Anderson \& Westneat, 2007). The use of this approach, or

338 other similar ones, for inferring body sizes of big placoderms can be preferable to the previous 
339

340

341

342

343

344

345

ones for two reasons: (1) the range of sizes of some living sharks is within the order of magnitude of sizes expected for $D$. terrelli, and (2) the mouth perimeter and body size are indirectly linked in marine predators by some ecological aspects such as the trophic level and prey size (e.g., Wainwright \& Richard, 1995; Scharf, Juanes \& Rountree, 2000; Karpouzi \& Stergiou, 2003). Therefore, mouth size or equivalent variables such as the upper jaw perimeter can be suitable predictors of body size when considering fishes that share similar feeding niches, as big predatory pelagic sharks and $D$. terrelli presumably do.

Reconstruction of Dunkleosteus terrelli caudal fin. Previous reconstructions of $D$. terrelli based on the anatomy of the smaller arthrodire placoderm Coccosteus (e.g., Heintz, 1932) could be inaccurate as this implies the comparison of taxa coming from too different facies and taxonomical assemblages and, ultimately, with possibly disparate lifestyles (Carr, 2010). In fact, Miles \& Westoll (1968) suggested that Coccosteus, although being well adapted to free swimming, would display also demersal habits using the bottom as an ambush site. Here, according to the pre-existing palaeoecological data and body size estimations of $D$. terrelli we propose a completely different reconstruction. Assuming ecological similarity with big living active pelagic sharks, our model predicts a caudal fin with a well-developed ventral lobe, high heterocercal and hypocercal angles, narrow peduncle and wide span (Fig. 4A). Interestingly, given the big size of this taxon, these inferences do not differ importantly if considering other less likely alternative scenarios as a slow-swimming benthopelagic lifestyle (i.e., assuming ecological analogy with squalomorph sharks (Fig. S2). This prediction gains support with the recent discovery of ceratotrichia in a pectoral fin of D. terrelli (Carr, Lelièvre \& Jackson, 2010). This finding implies that fins of placoderms could exceed the limits thought up to date, confined 
361 to the extension of the fin basal or radial elements, thus offering a greater range of

362 morphological variability and locomotor capabilities than previously suggested (Carr, Lelièvre \& 363 Jackson, 2010; Carr \& Jackson, 2010). In addition to caudal fin morphology, some other aspects

364 have been carefully considered with the aim of providing a fairly accurate whole reconstruction 365 of $D$. terrelli in accordance with the existing scientific evidence (Fig. 4B). The shape and 366 arrangement of the dermal plates as well as the position and extension of the sensory lines of

367 the cephalic shield are based on the study of the assembled specimen CMNH 6090. Pectoral fin 368 proportions follow the proposal of Carr, Lelièvre \& Jackson (2010), supported by observations 369 taken on partial articulated remains of this species. On the other hand, just a single dorsal fin is

370 represented in agreement to the condition shown by all the other arthoridire placoderms

371 where this structure is preserved (Denison, 1978). In this case, a phylogenetical-proximity

372 criterion is followed as the number of dorsal fins usually remains constant at order level both in 373 living and extinct fishes (Nelson, Grande \& Wilson, 2016). Finally, countershading coloration

374 and fusiform body, rather congruent with an active pelagic lifestyle, has been illustrated in 375 contraposition to more eye-catching and macruriform representations with the broadest part 376 of the body immediately behind the head (e.g., Heintz, 1932 fig. 90; Frickhinger, 1995 p. 136;

377 Cuny, 2013 fig. 7).

378 Comments on the importance of ecomorphology on palaeoartistic reconstructions

379 Palaeoart plays an essential role popularising palaeontology, generating a visual idea for the 380 general public of how extinct organisms were in life (Witton, Naish \& Conway, 2014). In this 381 sense, the use of rigorous methodologies and updated scientific information is essential for the 
382 production of accurate reconstructions and the appropriate scientific dissemination of the most 383 current knowledge in palaeobiology. Otherwise, imprecise representations can have very 384 negative effects, leading to misperceptions about extinct species that could become deeply rooted in the general public, especially in the case of taxa with great media impact (e.g., Glut \& Brett-Surman, 1997). Several procedures have been proposed in order to carry out realistic reconstructions supported by the available scientific knowledge (Paul, 1987; Paul \& Chase, 1989; Witmer, 1995; Sellers et al., 2009; Ghilardi \& Ribeiro, 2010). Among them, phylogenetic bracket approaches have been commonly applied for reconstructing non-preserved soft tissues and other palaeobiological aspects on the basis of maximum likelihood criterion by comparison with phylogenetically closely related taxa (e.g., Witmer, 1995). This kind of approach can be really useful for reconstructing characters with strong phylogenetic load that remain constant within the taxonomic group regardless of other factors. However, the application of such methodologies in a loose way, in order to make inferences about morphological characters without an osteological control or other palaeobiological aspects such as behaviour, physiology or ecology, requires a high level of speculation and is extremely sensitive to convergence. In those cases, the application of other approaches that imply a "briefing" (e.g., Ghilardi \& Ribeiro, 2010), aiming to integrate evidence from a broader spectrum of disciplines, could be more appropriate. In this sense, this work highlights the need of considering extant ecological analogues and palaeoecological data coming from biomechanical, taphonomical,

401 sedimentological and palaeobiogeographical studies for helping us to know what some fossil 402 early vertebrates looked like. Only in that way, their reconstructions will be in agreement not 403 only with their phylogenetic legacy but also with the ecomorphological patterns related to their 
404 particular lifestyles, waiting for the discovery of new remains that shed light on their real 405 appearance.

\section{ACKNOWLEDGEMENTS}

407 We would like to thank the palaeoilustrator Mr. Hugo Saláis (University of Valencia) for his 408 artistic contribution in Fig. 4; the Dr. Vélez-Zuazo (University of Puerto Rico) for making 409 available to us the phylogeny (NEXUS) files of Vélez-Zuazo \& Agnarsson (2011); and the Dr. Amanda McGee and Dr. Michael Ryan (Cleveland Museum) for providing to us the measurements of Dunkleosteus terrelli specimens. We are also thankful to Dr. Soledad De Esteban Trivigno (Institut Català de Paleontologia) and Borja Figueirido Castillo (Universidad de Málaga) for their comments on early versions of the manuscript and advice on the methodological approach. We acknowledge the comments of Dr. Claudia Marsicano (Academic Editor), Dr. Robert Carr and Dr. Thomas Fletcher (referees) and an anonymous reviewer that have considerably improved the 416 final manuscript.

\section{REFERENCES}

Albert JS, Johnson DM, Knouft JH. 2009. Fossils provide better estimates of ancestral body size than do extant taxa in fishes. Acta Zoologica 90:357-384.

Allison PA. 1986. Soft-bodied animals in the fossil record: The role of decay in fragmentation during transport. Geology 14:979-981.

Allison PA, Bottjer DJ. 2011. Taphonomy: bias and process through time. In: Allison PA, Bottjer DJ, eds. Topics in geobiology. New York: Springer, 1-17. 
424 Allison PA, Briggs DE. 1993. Exceptional fossil record: Distribution of soft-tissue preservation 425 through the Phanerozoic. Geology 21:527-530.

426 Altringham JD, Johnston IA. 1990. Scaling effects on muscle function: power output of isolated

427

428

429

430

431

432

433

434

435

436

437

438

439

440

441

442

443

444

445

fish muscle fibres performing oscillatory work. Journal of Experimental Biology 151:453467.

Altringham JD, Young IS. 1991. Power output and the frequency of oscillatory work in mammalian diaphragm muscle: the effects of animal size. Journal of Experimental Biology 157:381-389.

Anderson PS, Westneat MW. 2007. Feeding mechanics and bite force modelling of the skull of Dunkleosteus terrelli, an ancient apex predator. Biology Letters 3:77-80.

Anderson PS, Westneat MW. 2009. A biomechanical model of feeding kinematics for Dunkleosteus terrelli (Arthrodira, Placodermi). Paleobiology 35:251-269.

Arata GF. 1954. A contribution to the life history of the swordfish, Xiphias gladius Linnaeus, from the South Atlantic coast of the United States and the Gulf of Mexico. Bulletin of Marine Science 4:183-243.

Barron LS, Ettensohn FR. 1981. Paleoecology of the Devonian-Mississippian black-shale sequence in eastern Kentucky with an atlas of some common fossils. U.S. Department of Energy, Technical Information Center.

Breder CM. 1926. The locomotion of fishes. Zoologica 4: 159-256.

Briggs DE. 2003. The role of decay and mineralization in the preservation of soft-bodied fossils. Annual Review of Earth and Planetary Sciences 31:275-301.

Briggs DE, Kear AJ. 1993. Fossilization of soft tissue in the laboratory. Science 259:1439-1442. 
446 Carr RK. 1995. Placoderm diversity and evolution. Bulletin du Muséum d'Histoire Naturelle $447 \quad 17: 85-125$.

448 Carr RK. 2009. A big fish story: links between the Appalachian Basin and Morocco in the Late 449 Devonian. Cincinnati Museum Center Scientific Contributions 3:204.

450 Carr RK. 2010. Paleoecology of Dunkleosteus terrelli (Placodermi: Arthrodira). Kirtlandia, The $451 \quad$ Cleveland Museum of Natural History 57:36-55.

452 Carr RK, Jackson GL. 2010. The vertebrate fauna of the Cleveland Member (Famennian) of the Ohio Shale, Chapter 5. In: Hannibal JT, ed. Guide to the Geology and Paleontology of the Cleveland Member of the Ohio Shale. Cleveland: Ohio Geological Survey Guidebook, 1-17.

455

456

457

458

459

460

461

462

463

464

465

466

467

Carr RK, Lelièvre H, Jackson GL. 2010. The ancestral morphotype for the gnathostome pectoral fin revisited and the placoderm condition. In: Elliott DK, Maisey JG, Yu X, Miao D, eds. Morphology, phylogeny and paleobiogeography of fossil fishes. München: Verlag Dr Friedrich Pfeil, 107-122.

Compagno LV. 1990. Alternative life-history styles of cartilaginous fishes in time and space. Environmental Biology of Fishes 28:33-75.

Cuny G. 2013. Requins - De la préhistoire à nos jours. Paris: Belin litterature et revues.

Denison RH. 1978. Placodermi. Handbook of Paleoichthyology, vol. 2. Stuttgart: Gustav Fischer Verlag.

Donley JM, Sepulveda CA, Konstantinidis P, Gemballa S, Shadwick RE. 2004. Convergent evolution in mechanical design of lamnid sharks and tunas. Nature 429:61-65.

Donoghue PCJ, Sansom IJ. 2002. Origin and early evolution of vertebrate skeletonization. Microscopy research and technique 59:352-372. 
468 Donoghue PCJ, Sansom IJ., Downs JP. 2006. Early evolution of vertebrate skeletal tissues and 469 cellular interactions, and the canalization of skeletal development. Journal of Experimental 470 Zoology Part B: Molecular and Developmental Evolution 306:278-294.

471 Ebert DA, Fowler SL, Compagno L. 2013. Sharks of the World: A Fully Illustrated Guide.

$472 \quad$ Plymouth: Wild Nature Press.

473 Fletcher T, Altringham J, Peakall J, Wignall P, Dorrell R. 2014. Hydrodynamics of fossil fishes.

$474 \quad$ Proceedings of the Royal Society B: Biological Sciences 281: 20140703.

475 Frickhinger KA. 1995. Fossil atlas, fishes. Melle: Baensch.

476 Fu AL, Hammerschlag N, Lauder GV, Wilga CD, Kuo C-Y, Irschick DJ. 2016. Ontogeny of head and 477 caudal fin shape of an apex marine predator: The tiger shark (Galeocerdo cuvier). Journal 478 of morphology 277:556-564.

479 Ghilardi RP, Ribeiro RNS. 2010. The briefing in paleodesign: Selection and arrangement of data 480 for the reconstitution of paleovertebrates. Brazilian Geographical Journal: Geosciences and 481 Humanities research medium 1:1-20.

482

Glut DF, Brett-Surman MK. 1997. Dinosaurs and the media. In: Farlow JO, Brett-Surman MK, 483 eds. The Complete Dinosaur. Bloomongton and Indianapolis: Indiana University Press, 675697.

Gross W. 1960. Tityosteus n.gen. ein Reisenarthrodire aus dem rheinischen Unterdevon. Paläontologische Zeitschrift 34: 263-274.

487 Harper DA. 2008. Paleontological data analysis. Blackwell Publishing, Oxford. 
488 Heintz A. 1932. The structure of Dinichthys a contribution to our knowledge of the Arthrodira. $489 \quad$ Archaic fishes. In: Gudger EW, ed. Bashford Dean Memorial Volume. New York: American $490 \quad$ Museum of Natural History, 115-225.

491 Janvier P. 1996. Early vertebrates. Oxford: Oxford University Press.

492 Karpouzi VS, Stergiou KI. 2003. The relationships between mouth size and shape and body 493 length for 18 species of marine fishes and their trophic implications. Journal of fish biology $494 \quad 62: 1353-1365$.

495

496

497

498

499

500

501

502

503

504

505

506

507

508

509

Kidwell SM, Flessa KW. 1996. The quality of the fossil record: populations, species, and communities. Annual Review of Ecology and Systematics 26:269-299.

Klingenberg CP. 2011. MorphoJ: an integrated software package for geometric morphometrics. Molecular Ecology Resources 11:353-357.

Lamsdell JC, Braddy SJ. 2009. Cope's Rule and Romer's theory: patterns of diversity and gigantism in eurypterids and Palaeozoic vertebrates. Biology Letters rsbl20090700.

Langerhans RB, Reznick DN. 2010. Ecology and evolution of swimming performance in fishes: predicting evolution with biomechanics. In: Domenici P, Kapoor BG, eds. Fish locomotion: an eco-ethological perspective. Enfield: Science Publishers, 200-248.

Lindgren J, Caldwell MW, Konishi T, Chiappe LM. 2010. Convergent evolution in aquatic tetrapods: insights from an exceptional fossil mosasaur. PloS one 5:e11998.

Lindgren J, Kaddumi HF, Polcyn MJ. 2013. Soft tissue preservation in a fossil marine lizard with a bilobed tail fin. Nature Communications 4:2423.

Lindsey CC. 1978. Form, function and locomotory habits in fish. In: Hoar WS, Randall DJ, eds. Fish Physiology Vol. VII Locomotion. New York: Academic, 1-100. 
510 Lingham-Soliar T. 2005. Caudal fin allometry in the white shark Carcharodon carcharias:

511 implications for locomotory performance and ecology. Naturwissenschaften 92:231-236.

512 Long JA. 2010. The Rise of Fishes: 500 Million Years of Evolution. Johns Hopkins University Press.

513 Lowry D, de Castro ALF, Mara K, Whitenack LB, Delius B, Burgess GH, Motta P. 2009.

514 Determining shark size from forensic analysis of bite damage. Marine Biology, $515 \quad 156(12): 2483$.

516 Miles RS, Westoll TS. 1968. The Placoderm Fish Coccosteus cuspidatus Miller ex Agassiz from 517 the Middle Old Red Sandstone of Scotland. Part I. Descriptive Morphology. Earth and 518 Environmental Science Transactions of The Royal Society of Edinburgh 67:373-476.

519 Motani R. 2002. Scaling effects in caudal fin propulsion and the speed of ichthyosaurs. Nature $520 \quad 415: 309-312$.

521 Murdock DJ, Dong X-P, Repetski JE, Marone F, Stampanoni M, Donoghue PCJ. 2013. The origin 522 of conodonts and of vertebrate mineralized skeletons. Nature 502:546-549.

523 Nakamura I. 1985. FAO species catalogue. Vol. 5. Billfishes of the world. An annotated and 524 illustrated catalogue of marlins, sailfishes, spearfishes and swordfishes known to date. $525 \quad$ FAOFish. Synop. 125, 1-65.

526 Nelson JS, Grande TC, Wilson MVH. 2016. Fishes of the world. New Jersey: Wiley.

527 Olive S, Goujet D, Lelièvre H, Janvier P. 2014. The growth of the skull roof plates in Arabosteus 528 variabilis (Acanthothoraci, Placodermi) from the Early Devonian Jauf Formation (Saudi

529 Arabia): Preliminary results. Paleontological Journal 48:992-1002. 
530 Paul GS. 1987. The science and art of restoring the life appearance of dinosaurs and their

531 relatives: a rigorous how-to guide. In: Czerkas SJ, Olsen EC, eds. Dinosaurs past and

532 present. Seattle: University of Washington Press, 4-49.

533 Paul GS, Chase TL. 1989. Reconstructing extinct vertebrates. In: Hodges ERS, ed. The Guild

$534 \quad$ Handbook of Scientific Illustration. New York: Van Nostrand Reinhold, 239-256.

535 Raschi WG, Musick JA. 1986. Hydrodynamic aspects of shark scales. NASA Contractor Rep. 3963.

536 Rohlf FJ. 2004. TPSDig v. 1.4. Department of Ecology and Evolution, State University. Stony

$537 \quad$ Brook, New York.

538 Rohlf FJ. 2011. TPSRegr v. 1.41. Department of Ecology and Evolution, State University. Stony

$539 \quad$ Brook, New York.

540 Sansom IJ, Smith MP, Armstrong HA, Smith MM. 1992. Presence of the earliest vertebrate hard

541 tissues in conodonts. Science 256:1308-1311.

542 Scharf FS, Juanes F, Rountree RA. 2000. Predator size-prey size relationships of marine fish

543 predators: interspecific variation and effects of ontogeny and body size on trophic-niche

$544 \quad$ breadth. Marine Ecology Progress Series 208:229-248.

545 Seilacher A. 1991. Self-organizing mechanisms in morphogenesis and evolution. In: Schmidt-

$546 \quad$ Kittler N, Vogel K, eds. Constructional Morphology and Evolution. Berlin: SpringerVerlag, $547 \quad 251-271$.

548 Sellers WI, Manning PL, Lyson T, Stevens K, Margetts L. 2009. Virtual palaeontology: gait

549 reconstruction of extinct vertebrates using high performance computing. Palaeontologia

$550 \quad$ Electronica 12:12-3. 
551 Sepkoski D, Ruse M. 2009. The paleobiological revolution: essays on the growth of modern 552 paleontology. Chicago: University of Chicago Press.

553 Sfakiotakis M, Lane DM, Davies JBC. 1999. Review of fish swimming modes for aquatic

$554 \quad$ locomotion. IEEE Journal of oceanic engineering 24:237-252.

555 Sheets HD. 2014. IMP: CoordGen8- Coordinate Generation Utility. Dept. of Physics, Canisius 556 College, 2001 Main St., Buffalo, NY 14208.

557 Sire J-Y, Donoghue PCJ, Vickaryous MK. 2009. Origin and evolution of the integumentary 558 skeleton in non-tetrapod vertebrates. Journal of Anatomy 214:409-440.

559 Stensiö EA. 1963. Anatomical studies on the arthrodiran head. Part I. Kungliga Svenska $560 \quad$ Vetenskapsakademiens, Handlingar.

561 Thomson KS. 1971. The adaptation and evolution of early fishes. The Quarterly Review of 562 Biology 46:139-166.

563 Thomson KS, Simanek DE. 1997. Body form and locomotion in sharks. American Zoologist $564 \quad 17: 343-354$.

565 Trinajstic KM, Hazelton M. 2007. Ontogeny, phenotypic variation and phylogenetic implications 566 of arthrodires from the Gogo Formation, Western Australia. Journal of Vertebrate 567 Paleontology 27:571-583.

568 Trinajstic KM, McNamara KJ. 1999. Heterochrony and phylogenetic trends. Records of the $569 \quad$ Western Australian Museum 57:93-106.

570 Vaškaninová V, Kraft P. 2014. The largest Lower Devonian placoderm Antineosteus rufus sp. 571 nov. from the Barrandian area (Czech Republic). Bulletin of Geosciences 89:635-644. 
572 Vélez-Zuazo X, Agnarsson I. 2011. Shark tales: a molecular species-level phylogeny of sharks 573 (Selachimorpha, Chondrichthyes). Molecular Phylogenetics and Evolution 58:207-217.

574 Von Cramon-Taubadel N, Frazier BC, Lahr MM. 2007. The problem of assessing landmark error 575 in geometric morphometrics: theory, methods, and modifications. American journal of 576 physical anthropology 134:24-35.

577 Wainwright PC, Richard BA. 1995. Predicting patterns of prey use from morphology of fishes. $578 \quad$ Environmental Biology of Fishes 44:97-113.

579 Wardle CS. 1975. Limit of fish swimming speed. Nature 255:725-727.

580 Webb PW. 1975. Hydrodynamics and energetics of fish propulsion. Bulletin Fisheries Research $581 \quad$ Board of Canada 190:1-158.

582 Webb PW. 1984. Body form, locomotion and foraging in aquatic vertebrates. American $583 \quad$ Zoologist 24:107-120.

584 Webb PW. 1988. Simple physical principles and vertebrate aquatic locomotion. American $585 \quad$ zoologist 28:709-725.

586 Webb PW, De Buffrénil V. 1990. Locomotion in the biology of large aquatic vertebrates. 587 Transactions of the American Fisheries Society 119:629-641.

588 Werdelin L, Long JA. 1986. Allometry in the placoderm Bothriolepis canadensis and its $589 \quad$ significance to antiarch evolution. Lethaia 19:161-169.

590 Williams ME. 1990. Feeding behavior in cleveland shale fishes. In: Boucot AJ, ed. Evolutionary 591 paleobiology of behavior and coevolution. New York: Elsevier, 273-287. 
592 Witmer LM. 1995. The extant phylogenetic bracket and the importance of reconstructing soft 593 tissues in fossils. In: Thomason JJ, ed. Functional Morphology in Vertebrate Paleontology. 594 Cambridge: Cambridge University Press, 19-33.

595 Witton MP, Naish D, Conway J. 2014. State of the palaeoart. Palaeontologia Electronica 17:5E.

596 Young GC. 2005. A new Middle Devonian arthrodire (placoderm fish) from the Broken River 597 area, Queensland. Records of the Australian Museum 57:211-220.

598 Zhu M, Janvier P. 1996. A small antiarch, Minicrania lirouyii gen. et sp. nov., from the Early 599 Devonian of Qujing, Yunnan (China), with remarks on antiarch phylogeny. Journal of $600 \quad$ Vertebrate Paleontology 16:1-15. 


\section{Figure 1}

Descriptive diagrams showing $(A-B)$ the landmark and wireframe configurations used in the geometric morphometric analyses of sharks and (C-D) the variables considered for the total body length estimations of Dunkleosteus terrelli.

Position of the landmarks (red points) and wireframe configurations (red dashed lines) chosen for the analyses of (A) the whole group of sharks and the ecological subgroups of demersal and squalomorph species; and (B) the ecological subgroup of active pelagic species. Shark drawings modified from Ebert, Fowler \& Compagno (2013). Landmark 1, tip of the snout. Landmark 2, most posterior part of the eye. Landmark 3, uppermost part of the first gill opening. Landmark 4, pectoral fin origin. Landmark 5, lowest point on dorsal border of the caudal peduncle. Landmark 6, distal tip of the dorsal caudal-fin lobe. Landmark 7 , distal tip of the ventral caudal-fin lobe. Landmark 8, highest point on ventral border of the caudal peduncle. Landmark 9, uppermost part of the fifth gill opening. Landmark 10, caudal fin posterior notch. Landmarks 1, 4-8 are type 2 and landmarks 2, 3 and 9 are type 1 . (C) Upper Jaw Perimeter (UJP) measurement taken on the $D$. terrelli assembled specimens (CMNH 5768, CMNH 7424, CMNH 6090, CMNH 7054) and (D) Jaw Measurements (JMs) taken on the $D$. terrelli inferognathals. D. terrelli drawings modified from Carr \& Jackson (2010). PN, postnasal plate; $\mathrm{R}$, rostral plate; $\mathrm{SO}$, suborbital plate; asterisks indicate the position of the quadratomandibular articulation. 
A

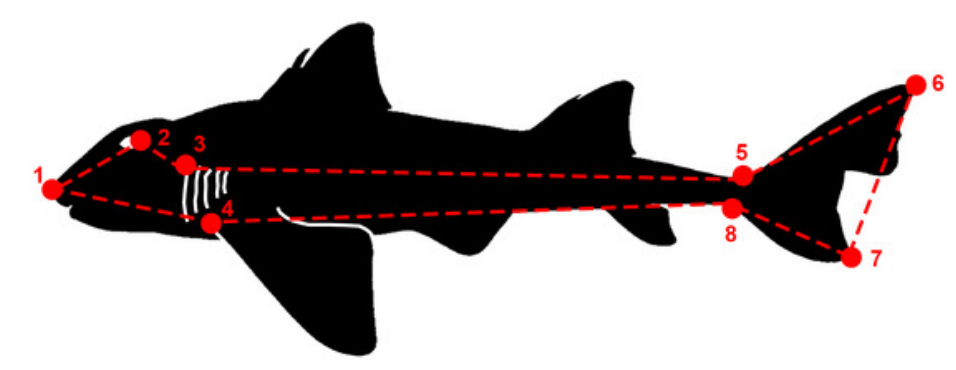

B

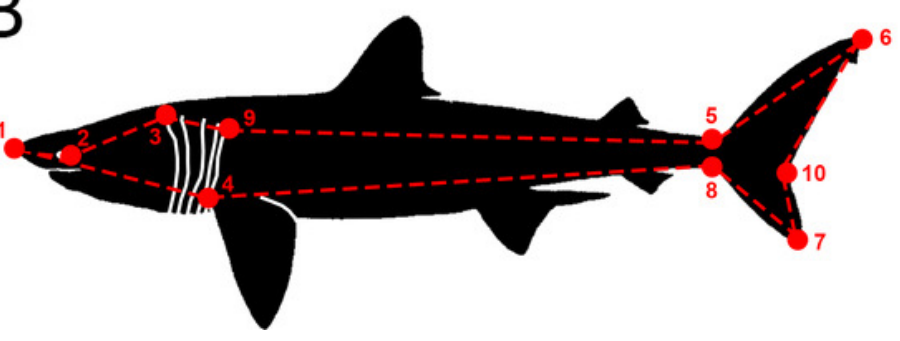

C
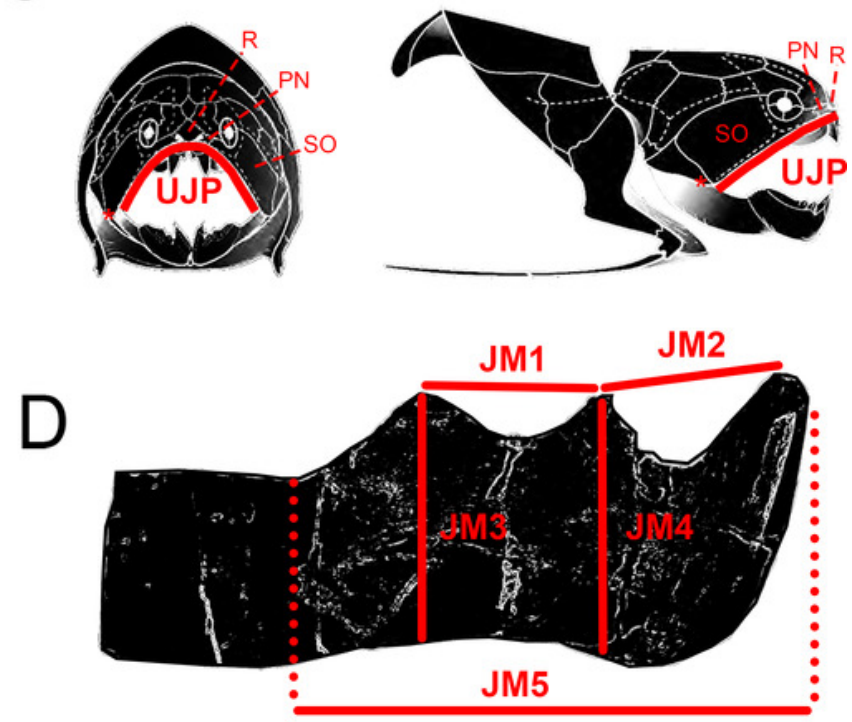
Figure 2

Principal Component Analysis (PCA) results for the whole group of sharks.

PCA plots of the first two PC axes showing the distribution of $(A)$ taxonomic groups at order level and (B) modes of life according to Thomson \& Simanek (1997). The phylogenetic tree (modified from Vélez-Zuazo \& Agnarsson, 2011) is mapped into the PCA morphospace.

Wireframe configurations show shape changes from the negative to the positive extreme of the axes (black and red respectively).

A

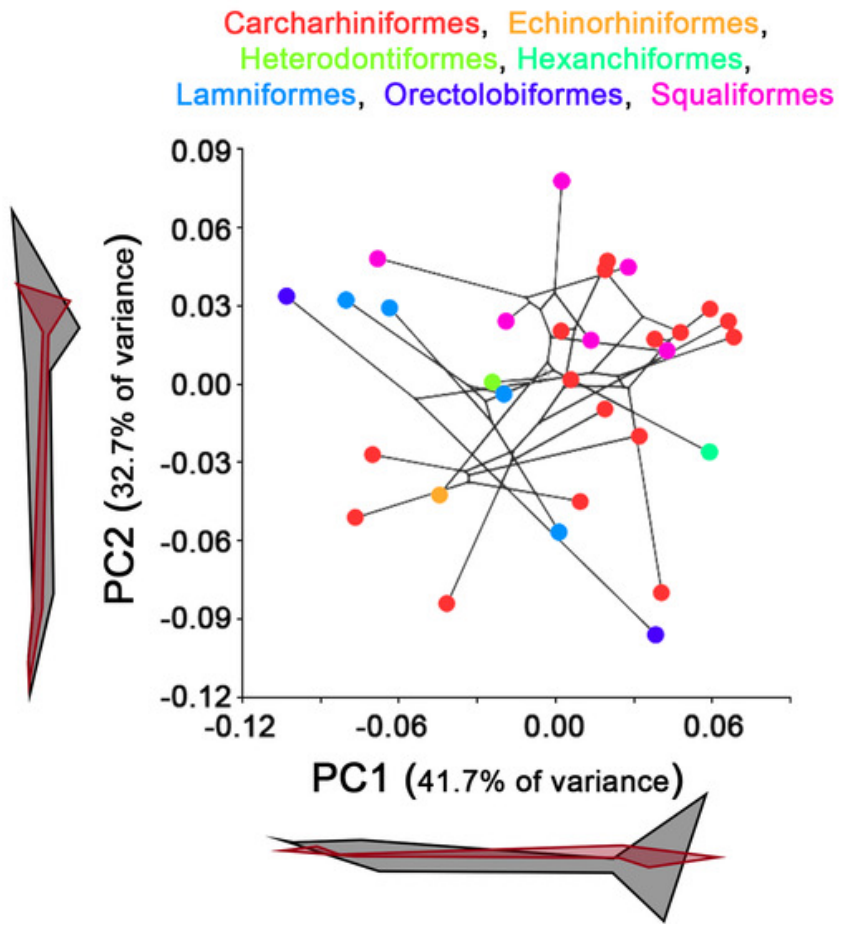

B

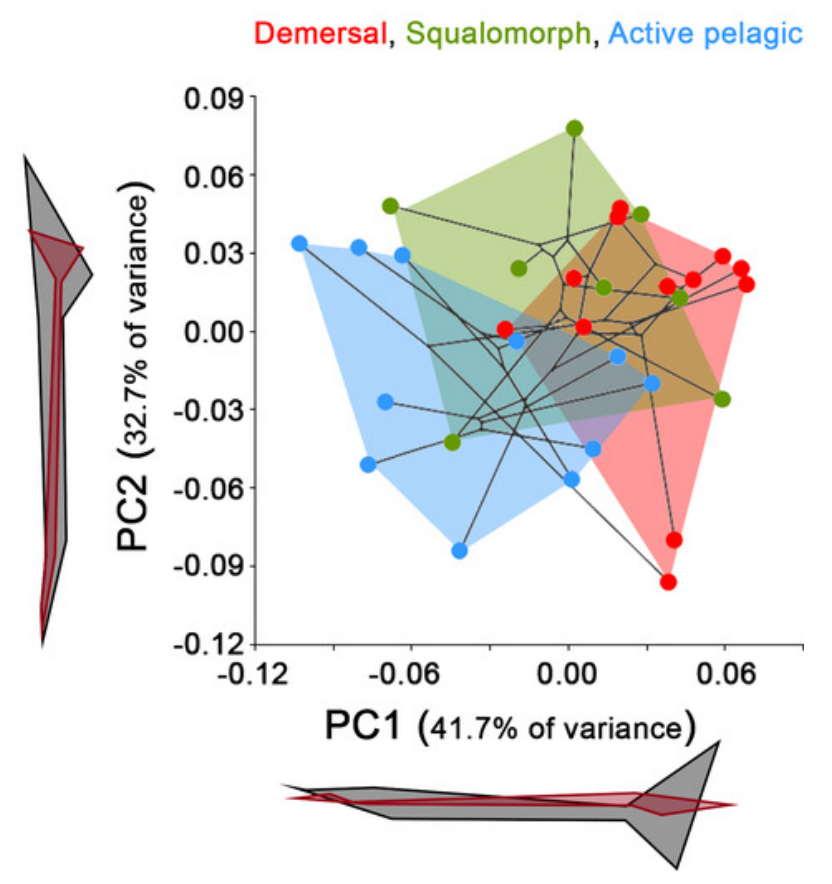


Figure 3

Allometric regression analysis results for $(A)$ the whole group of sharks and the ecological subgroups of (B) demersal, (C) squalomorph and (D) active pelagic shark species.

Wireframe configurations show shape changes from the negative to the positive extreme of the axis (black and red respectively). Upper and lower limits of 95\% mean confidence intervals are showed with dashed lines for each regression analysis.
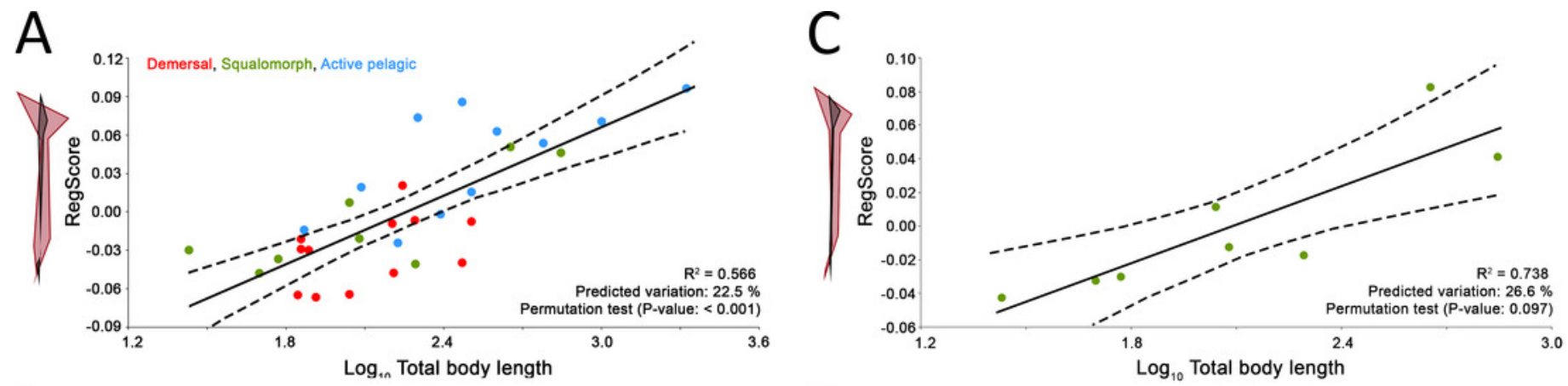

B
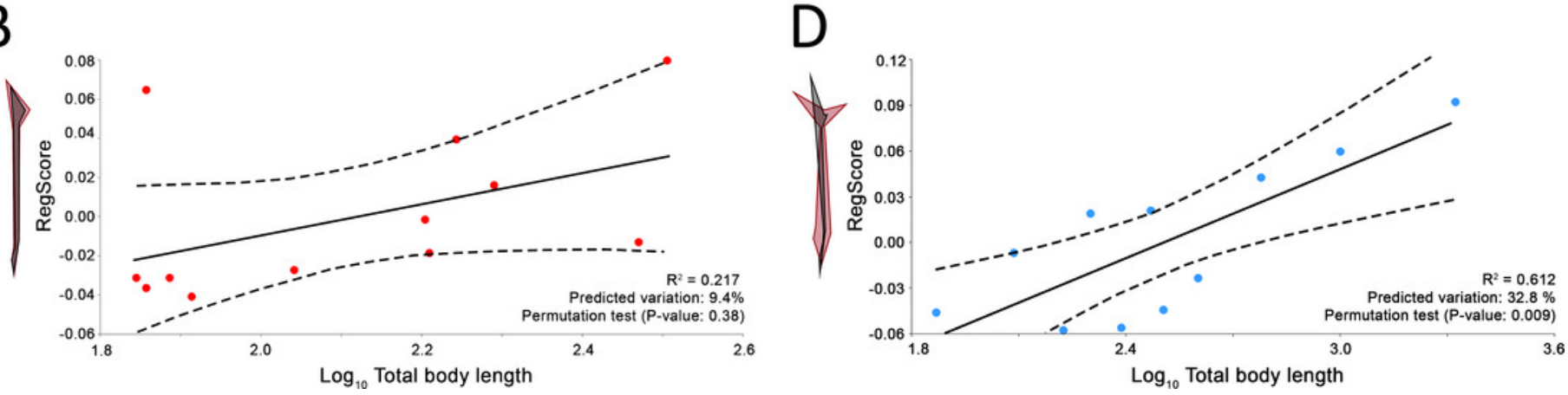


\section{Figure 4}

Caudal fin shape inferences in Dunkleosteus terrelli.

(A) Predicted caudal fin shape of each specimen of $D$. terrelli (in black), showing the upper and lower $90 \%$ individual confidence interval boundaries (in red and blue respectively). (B) Palaeoartistic reconstruction of a 8.79 meters D. terrelli (courtesy of Hugo Salais, HS

Scientific Illustration).

A

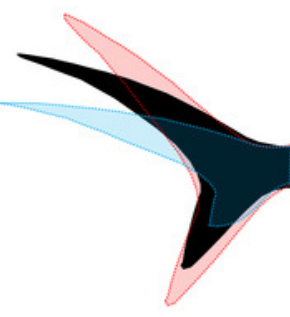

CMNH 7424

Total body length: $320 \mathrm{~cm}$

Heterocercal angle: $22^{\circ}$

Hipocercal angle: $44^{\circ}$

Dorsal lobe: $80 \mathrm{~cm}$

Ventral lobe: $38 \mathrm{~cm}$



CMNH 6090

Total body length: $534 \mathrm{~cm}$ Heterocercal angle: $26^{\circ}$ Hipocercal angle: $45^{\circ}$ Dorsal lobe: $132 \mathrm{~cm}$ Ventral lobe: $69 \mathrm{~cm}$

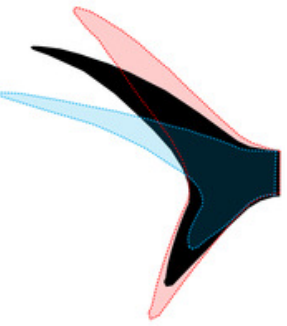

CMNH 7054

Total body length: $576 \mathrm{~cm}$ Heterocercal angle: $27^{\circ}$

Hipocercal angle: $45^{\circ}$

Dorsal lobe: $142 \mathrm{~cm}$

Ventral lobe: $75 \mathrm{~cm}$



CMNH 5768

Total body length: $688 \mathrm{~cm}$ Heterocercal angle: $28^{\circ}$

Hipocercal angle: $46^{\circ}$

Dorsal lobe: $170 \mathrm{~cm}$

Ventral lobe: $94 \mathrm{~cm}$

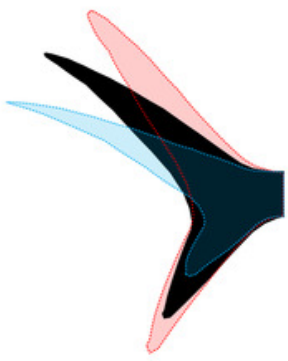

CMNH 5936

Total body length: $879 \mathrm{~cm}$ Heterocercal angle: $30^{\circ}$

Hipocercal angle: $47^{\circ}$

Dorsal lobe: $216 \mathrm{~cm}$

B

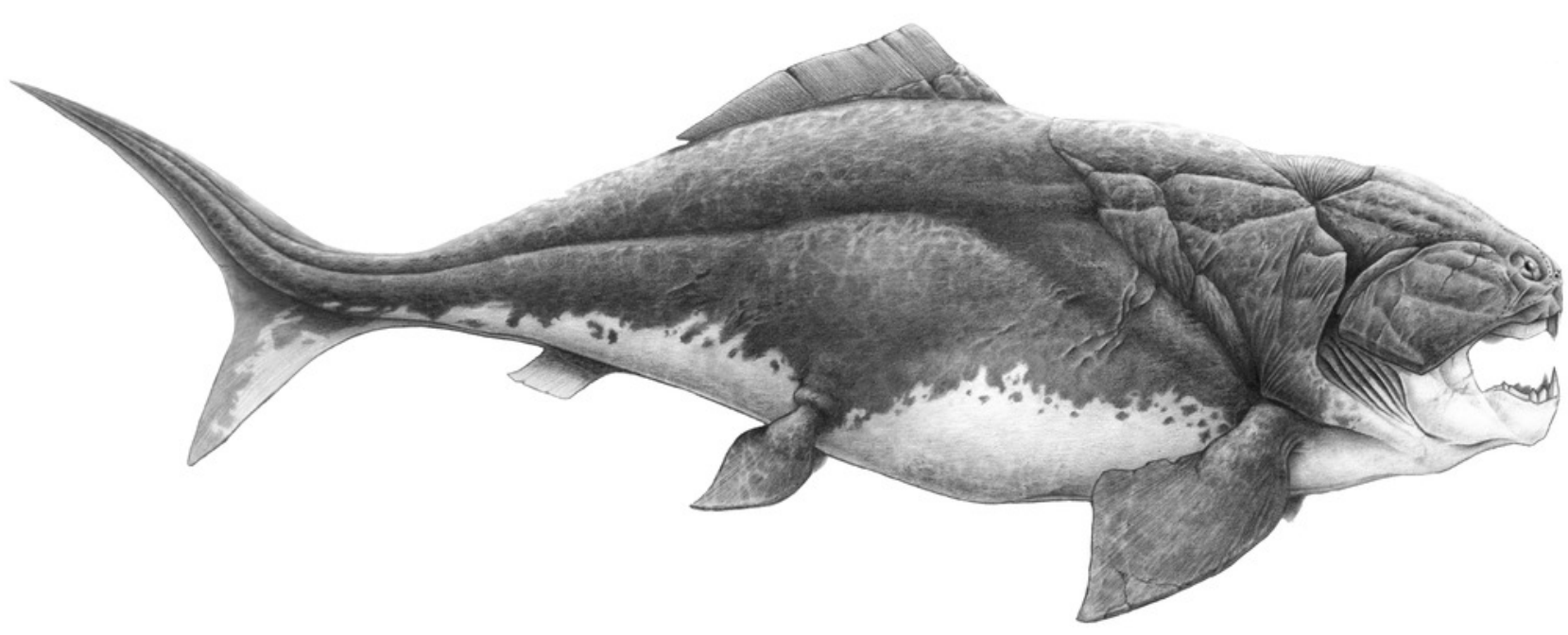




\section{Table 1 (on next page)}

Upper Jaw Perimeter (UJP) and Jaw Measurements (JM) of Dunkleosteus terrelli assembled specimens. 
Specimen UJP $(\mathrm{cm}) \quad J M 1(\mathrm{~cm}) \quad J M 2(\mathrm{~cm}) \quad J M 3(\mathrm{~cm}) \quad J M 4(\mathrm{~cm}) \quad J M 5(\mathrm{~cm})$

CMNH 5768120.0

14.0

9.5

17.0

15.0

27.0

CMNH 742451.0

6.5

8.5

7.0

13.3

CMNH 609091.0

11.0

4.5

11.5

12.0

20.0

CMNH 705499.0

10.0

8.5

13.5

$14.0 \quad 23.0$

1 


\section{Table 2 (on next page)}

Regression results between Upper Jaw Perimeter (UJP) and Jaw Measurements (JM) of Dunkleosteus terrelli assembled specimens and inferred values of UJP for the inferognathal specimen CMNH 5936. 


$\begin{array}{llll}\text { Regression } & \text { Equation } & \mathrm{R}^{2} & \text { CMNH 5936 UJP }(\mathrm{cm}) \\ \text { UJP * JM1 } & \mathrm{y}=8.963 \mathrm{x}-2.7407 & 0.9208 & 118.3 \\ \text { UJP * JM2 } & \mathrm{y}=13.084 \mathrm{x}-6.2423 & 0.9704 & 163.8 \\ \text { UJP * JM3 } & \mathrm{y}=7.8265 \mathrm{x}-8.5597 & 0.9346 & 140.1 \\ \text { UJP * JM4 } & \mathrm{y}=7.9737 \mathrm{x}-5.4342 & 0.9653 & 146.1 \\ \text { UJP * JM5 } & \mathrm{y}=4.9664 \mathrm{x}-13.176 & 0.9872 & 155.7\end{array}$

